Supplement of Clim. Past, 11, 1127-1137, 2015

http://www.clim-past.net/11/1127/2015/

doi:10.5194/cp-11-1127-2015-supplement

(C) Author(s) 2015. CC Attribution 3.0 License.

(c) (i)

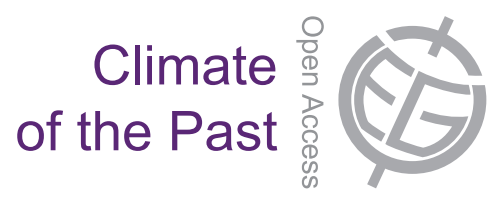

Supplement of

\title{
On the occurrence of annual layers in Dome Fuji ice core early Holocene ice
}

\section{A. Svensson et al.}

Correspondence to: A. Svensson (as@gfy.ku.dk)

The copyright of individual parts of the supplement might differ from the CC-BY 3.0 licence. 


\section{On the occurrence of annual layers in Dome Fuji ice core early Holocene ice}

\section{Supplement}

Conductivity $(\mu \mathrm{S} / \mathrm{cm}) \quad$ Ammonium (ppb) Sodium (ppb) Dust $\left(\mathrm{ml}^{-1}\right)$

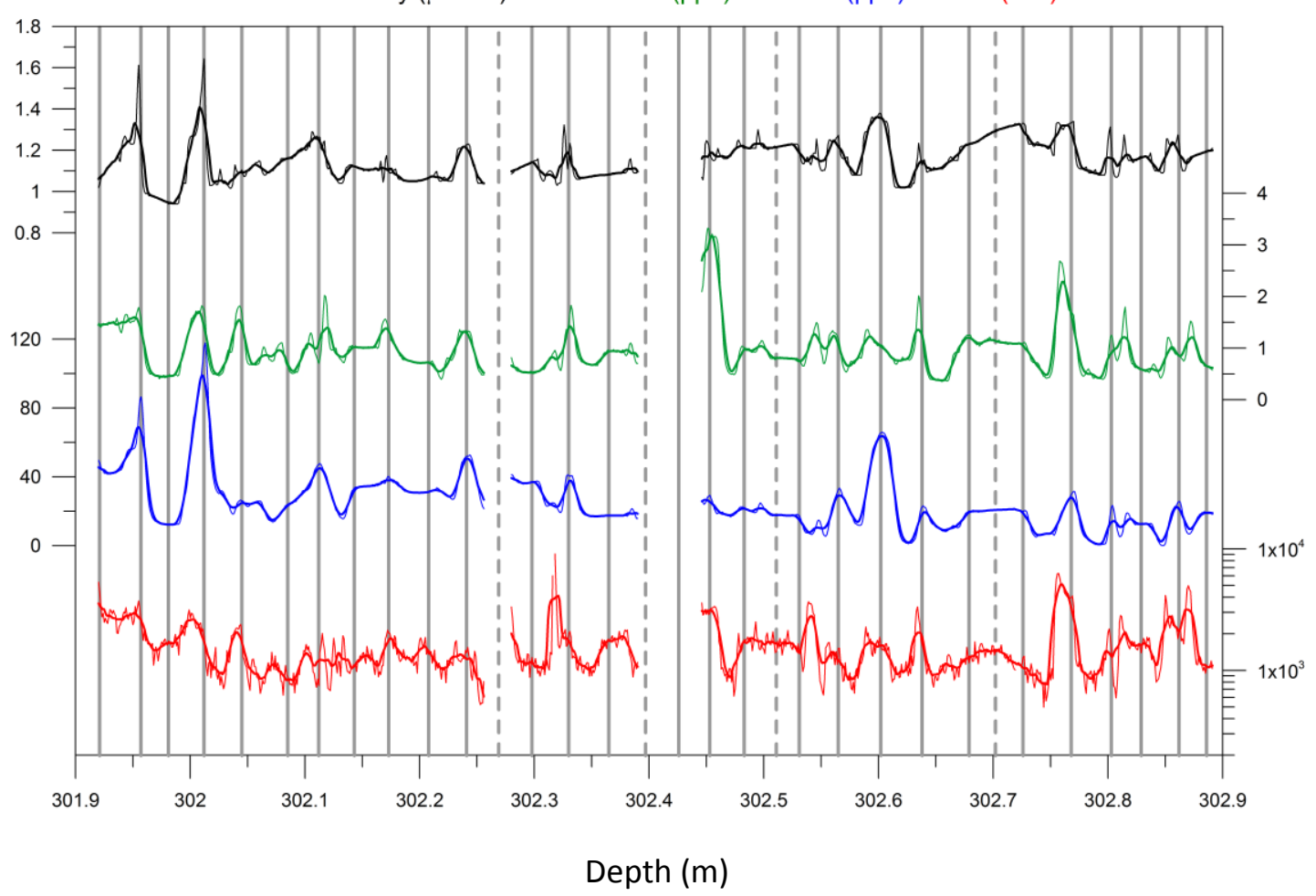

Conductivity $(\mu \mathrm{S} / \mathrm{cm}) \quad$ Ammonium $(\mathrm{ppb})$ Sodium $(\mathrm{ppb}) \quad$ Dust $\left(\mathrm{ml}^{-1}\right)$

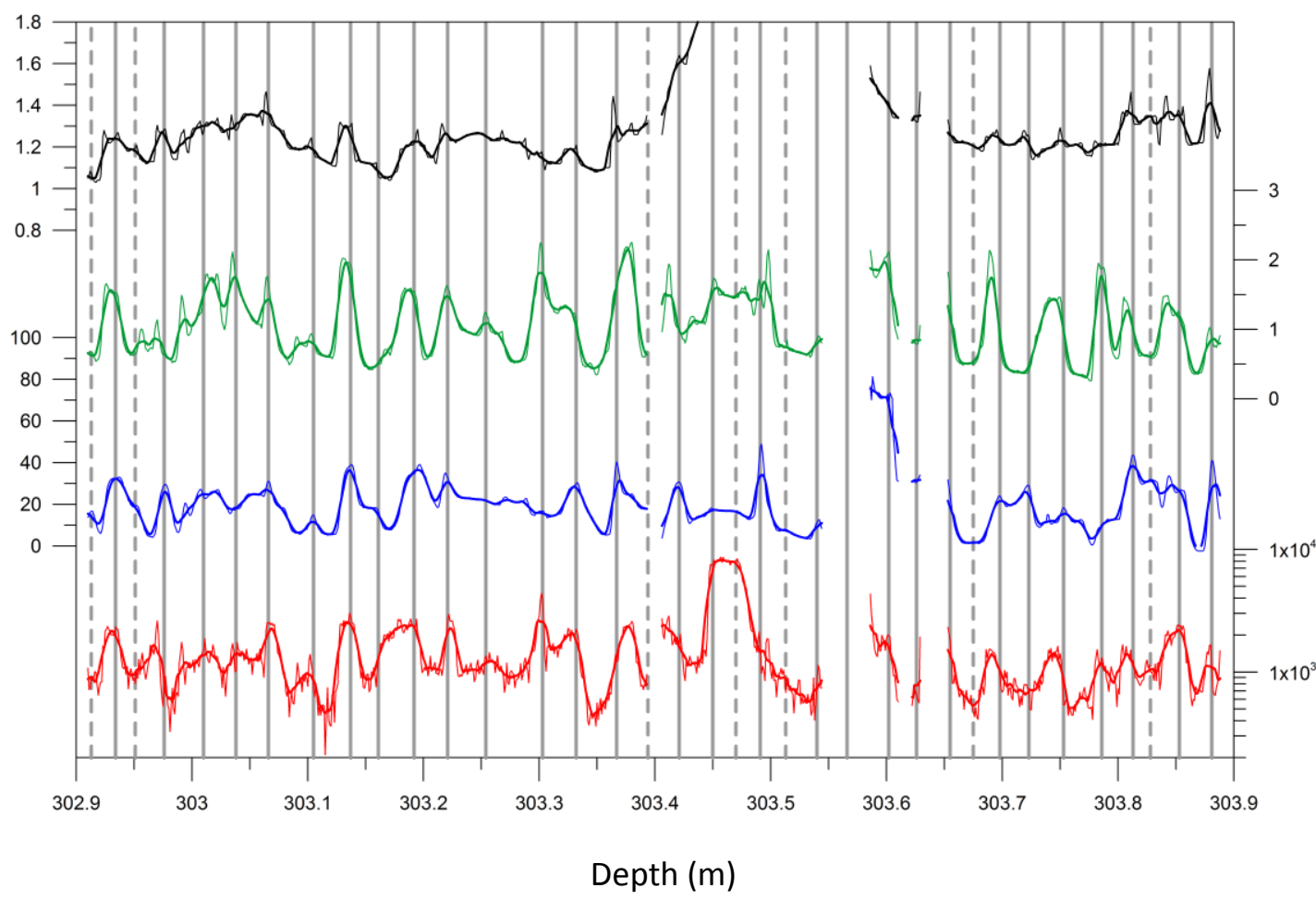




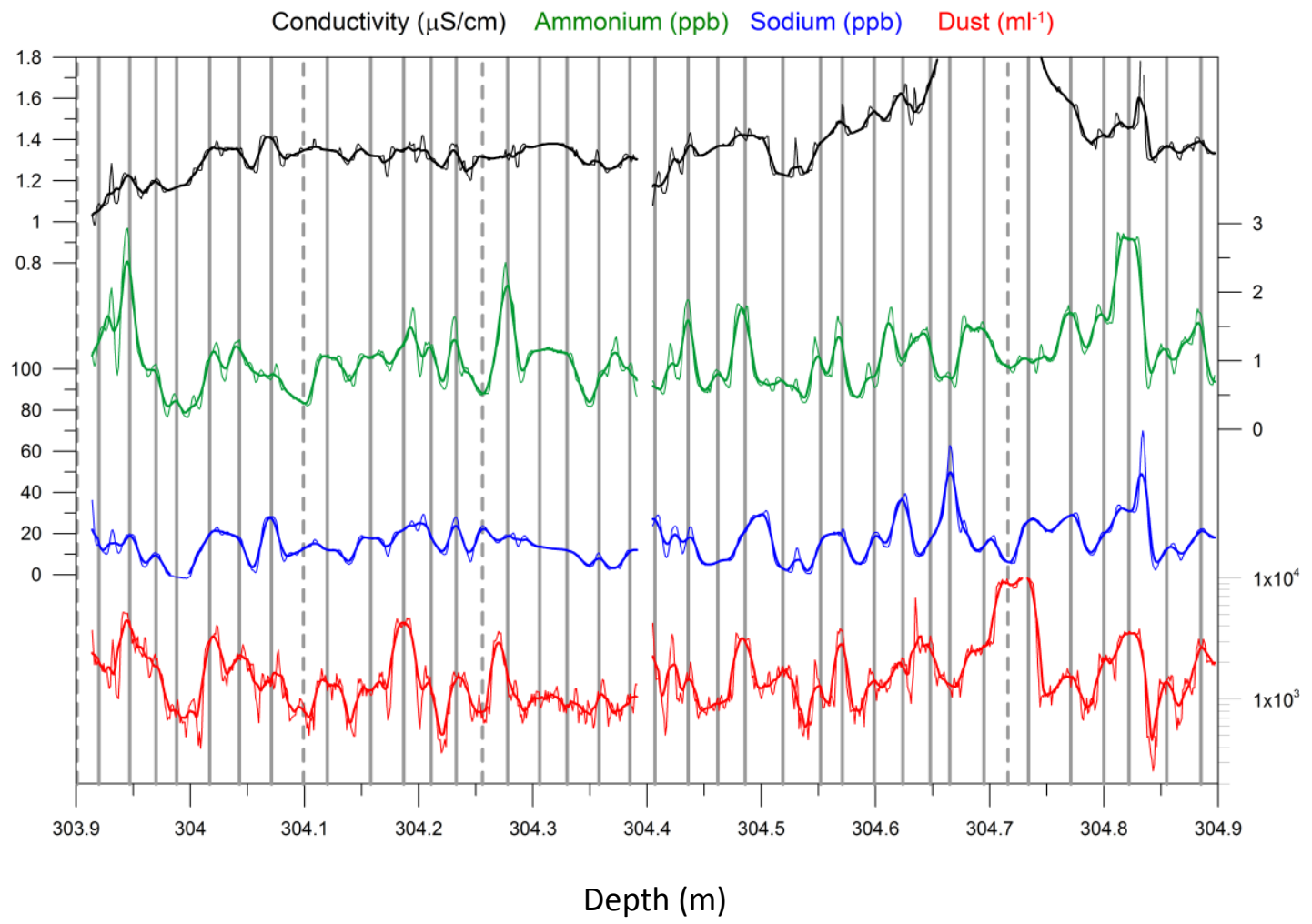

Conductivity $(\mu \mathrm{S} / \mathrm{cm}) \quad$ Ammonium (ppb) Sodium (ppb) Dust $\left(\mathrm{ml}^{-1}\right)$

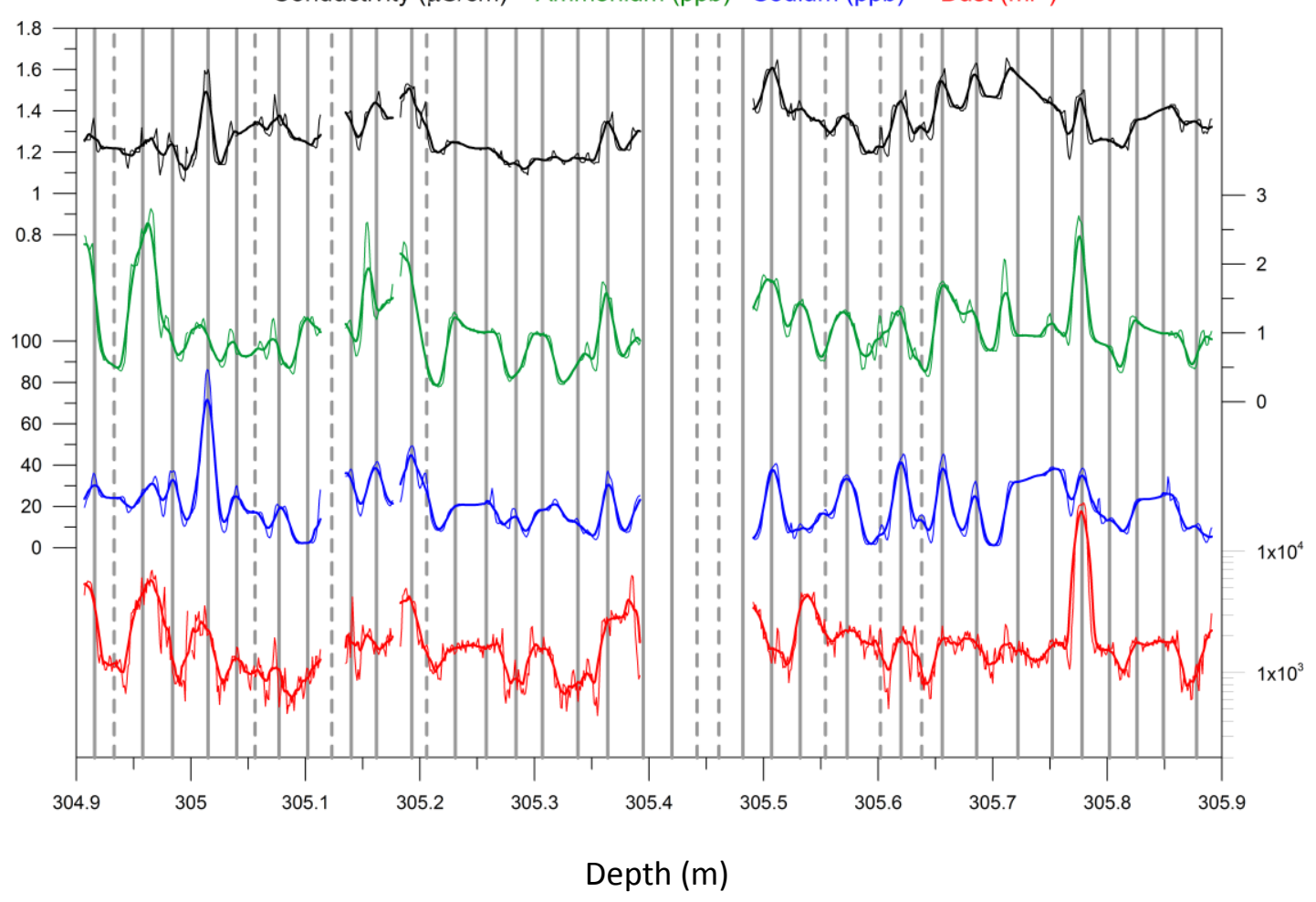




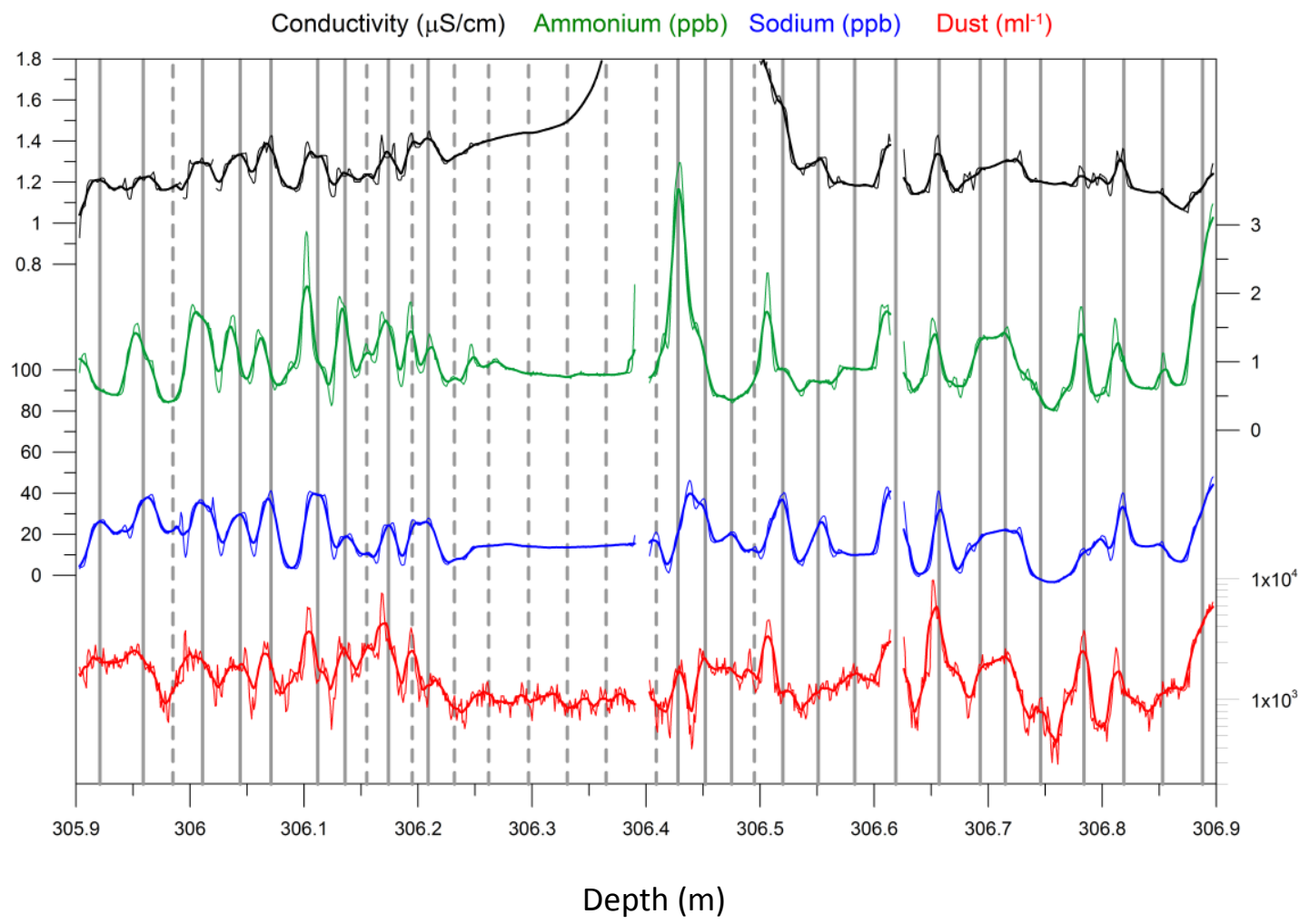

Figures S1-S5 showing the analysed $5 \mathrm{~m}$ of CFA records in high resolution including suggested layer marks. 


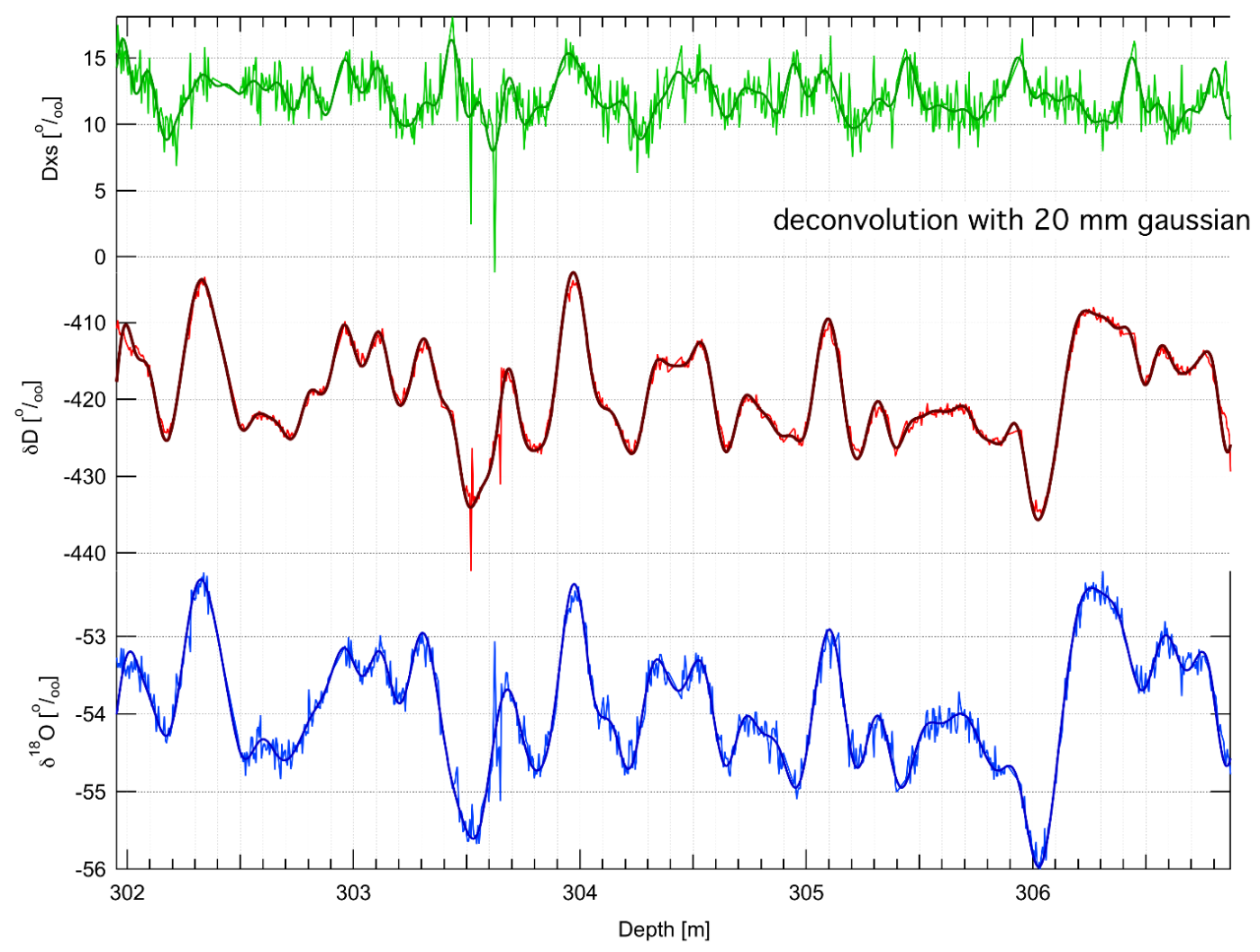

Figure S6. Continuously measured water isotopes $\delta^{18} \mathrm{O}$ and $\delta \mathrm{D}$ as well as the derived deuterium excess (Dxs). 